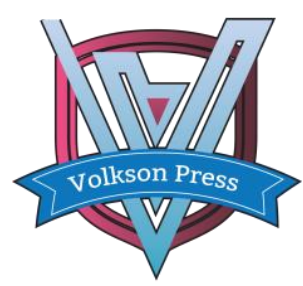

\title{
Empirical Analysis of Customer Repeat Purchase Forecast on 020 platform
}

\author{
Dai Yi-sheng1, Da Qiang1,*
}

1(School of Economics and Management, Jiangsu University of Science and Technology, Zhenjiang 212003, China)

*1508072212@qq.com

This is an open access article distributed under the Creative Commons Attribution License, which permits unrestricted use, distribution, and reproduction in any medium, provided the original work is properly cited.

\section{ARTICLE DETAILS}

\section{Article History:}

Received 02 october 2017 Accepted 06 october 2017 Available online 11 october 2017

\section{Keywords:}

O20 platform; NBD model; SMC model; customer repeat purchase forecast.

\section{ABSTRACT}

On the 020 platform, accurate forecasting of customer repeat purchase is critical to the management of these businesses. Based on the NBD model and SMC model, and taking nearly thousands of different categories of businesses on the 020 platform "koubei" as study object, we implement empirical research on customer repeat purchase forecast. The main contents include: (1) the introductions about NBD and SMC model; (2) forecasting the customer repeat purchase of different categories of businesses based on the models and analyzing the models fitting; (3) analyzing the models applicability based the results. The results shows that, in addition to the hot pot category, predicted results of the SMC model in each category of business is better than the NBD model, while the NBD model is more excellent in the forecast of the hot pot category.

\section{Introduction}

With the rapid development of 020 e-commerce, online and offline combined more closely. 020 platforms combine offline business opportunities with the Internet to make the Internet a trading desk of offline business, let consumers enjoy goods or services offline. ${ }^{[1]}$ In this model, the retail and catering industries are the most active several industries. Accurate forecasting of customer repeat purchase is critical to the management of these businesses since the competition grew. Based on the results of the forecast, businesses can improve business operational efficiency, reduce cost and improve the user experience. Most of the previous research focused on individual business-level customer traffic forecasts, lacking of large-scale, many categories and systematic research.[2-3] We classified nearly 2000 merchants on the 020 platform "koubei", conducting a large-scale predictive empirical study based on data collected from these businesses. At present on behalf of the model to solve the problem of predicting customer repeat purchase mainly with NBD model, SMC model, etc. ${ }^{[4-7]}$ Based on the NBD model and the SMC model, this paper compares the prediction results of the two models to find out the customer repeat purchase forecast model which is more suitable for each classified business.

\section{Model Introductions}

\subsection{Introduction to NBD Model}

The NBD model is based on the following three assumptions:

(1) Individual repeat purchase is distributed Poisson distribution with a purchase rate of $\lambda$.

(2) Transaction rates $(\lambda)$ are distributed across the population according to a gamma distribution with parameters $a$ and $b$.

(3) Stability. The purchase rate $(\lambda)$ of a single customer is determined once again.

\section{It follows that}

Let $X(t)$ be the number of events occurring in the interval $[0, T]$. More specifically, we are interested in $\mathrm{E}[\mathrm{Y}(\mathrm{t}) \mid$ data], the expected number of transactions in an adjacent period [ $\mathrm{T}, \mathrm{T}+\mathrm{t}]$, conditional on the observed purchase history.

$$
\text { EY }(t) \mid X=x, T, a, b)=\left(\frac{a+x}{b+T}\right) t
$$

\subsection{Introduction to SMC Model}

The SMC model is based on the following three assumptions:

(1) Individual repeat purchase is distributed Poisson distribution with a purchase rate of $\lambda$.

(2) Transaction rates $(\lambda)$ are distributed across the population according to a gamma distribution with parameters $\alpha$ and $\beta$.

(3) Individual repeat purchase is distributed exponential distribution with a purchase rate of $\mu$.

(4) Heterogeneity in dropout rates across customers follows a gamma distribution with shape parameter $s$ and scale parameter $\beta$.

(5) The transaction rate $\lambda$ and the dropout rate $\mu$ vary independently across customers.

It follows that

Let $\mathrm{E}\left(\mathrm{Y}(\mathrm{t}) \mid \mathrm{X}=\mathrm{x}, \mathrm{t}_{\mathrm{x}}, \mathrm{T}\right)$ denote the expected number of transactions in the period $[\mathrm{T}, \mathrm{T}+\mathrm{t}]$ for an individual with observed behavior $\left(\mathrm{X}=\mathrm{x}, \mathrm{t}_{\mathrm{x}}, \mathrm{T}\right)$. This conditional expectation is given by

$$
\begin{aligned}
& \text { EY } \left.(t) \mid X=x, t_{x}, T, r, \alpha, s, \beta\right) \\
& =\frac{\frac{s+\beta+x-1}{s-1}\left[1-\left(\frac{\alpha+T}{\alpha+T+t}\right)^{r+x}{ }_{2} F_{1}\left(r+x, \beta+x, s+\beta+x-1, \frac{1}{\alpha+T+t}\right)\right]}{1-\delta_{x>0} \frac{\alpha}{\beta+x-1}\left(\frac{\alpha+T}{\alpha+t_{x}}\right)^{r+x}}
\end{aligned}
$$

\section{Empirical Analysis}

\subsection{Data Description}

In this paper, the experimental data comes from the Tianchi Big Data Contest "IJCAI-17 koubei Merchant Flow Forecast Contest" published in 2017. The data sets combines business and customer data, including: business id, user id, user payment behavior, score, number of reviews, category, and store levels. The variables and their descriptions are shown in table 3.1. 


\begin{tabular}{llll}
\hline Number & Variables & Data types & Data description and remarks \\
\hline 1 & Shop id & Number & ID: $1 \sim 2000$ \\
2 & User id & Number & Sample : 0000000001 \\
3 & Times tamp & Number & Sample : 2015-10-10 10:00:00 \\
4 & Per pay & Number & $1 \sim 20$ \\
5 & Comment & Number & $0 \sim 20$ \\
6 & Shop level & Number & $0 \sim 2$ \\
7 & Cate_1_name & Factor & 6 categories, Sample : food \\
8 & Cate_2_name & Factor & 17 categories, Sample : snack \\
9 & Cate_3_name & Factor & 43 categories, Sample : other snack \\
\hline
\end{tabular}

\subsection{The Data Processing}

In this study, the customer data for the 2015-7-1 to 2016-10-31 during a total of 70 weeks (missing one day), to filter the data first, excluding 2000 stores in the 2015-7-1-2015-7-1 (before 28 weeks) without business records of merchants. Leaving more than 1,200 eligible businesses, these businesses refer to the original three categories of re-classification of the classification, divided into 12 categories. The summary results are shown in Table 3.3.

\section{Table 3.2 Frequency Statistics of Categorical Variables}

\begin{tabular}{llll}
\hline Number & Categorical variables & Frequency statistics & percentage \\
\hline 1 & The convenience store & 132 & 10.95 \\
2 & The supermarket & 218 & 18.08 \\
3 & Hot pot & 15 & 1.24 \\
4 & Chinese food & 38 & 3.15 \\
5 & Chinese fast food & 120 & 9.95 \\
6 & Western fast food & 340 & 28.19 \\
7 & The cake & 34 & 2.82 \\
8 & Bread & 40 & 3.32 \\
9 & Snacks & 91 & 7.55 \\
10 & Milk tea & 51 & 4.23 \\
11 & Dessert/drinks & 46 & 3.81 \\
12 & Fresh fruit & 81 & 6.72 \\
\hline
\end{tabular}

Each business was sampled for the first time from 42 July 2015 to April 2016, with the observation period ending in July 2016 for 56 weeks. The initial purchase time is set to 0.2016 July to October a total of 14 weeks as a verification period, the time period is set as shown.

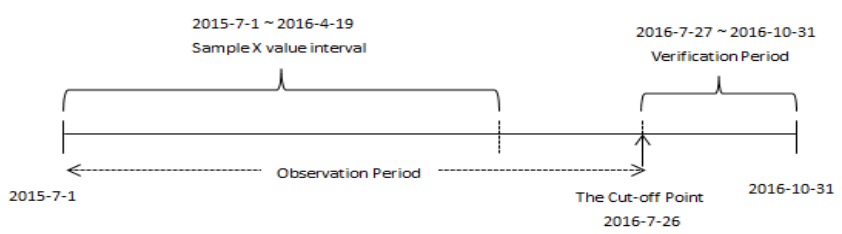

Figure 3.1 Time Section Setting Up

\subsection{Parameters estimation}

In this paper, the maximum likelihood estimation method is used to estimate the parameters and the R language and MATLAB 7.8.0 are used as the tool for parameter estimation and prediction. ${ }^{\left[{ }^{[8}\right]}$

\subsection{Empirical Results}

In order to test the effectiveness of models for forecasting of customer repeat purchase, we compare the predicted value of the customer repeat purchase in each merchant with the true value. We test the models on the effectiveness of the classification of the customer repeat purchase prediction by calculating the root mean square error (RMSE).We calculate the NBD model and SMC model RMSE value of the maximum, minimum, mean, median, quartile and other statistical information. The results are shown in Table 3.3 and Table 3.4.

Table 3.3 Summary of RMSE for Different Types of Shops

\begin{tabular}{lllllll}
\hline Number & Categorical variables & Max & Min & Mean & Median & $1^{\text {st }} \mathrm{Qu}$ \\
\hline 1 & & & & & & \\
\hline & The convenience store & 15.5510 & 0.5561 & 4.0545 & 3.7632 & 2.9431 \\
& The supermarket & 8.2041 & 0.3499 & 2.6884 & 2.6230 & 2.1914 \\
3 & Hot pot & 2.0570 & 0.4999 & 0.7755 & 0.6145 & 0.5394 \\
& & & & & & \\
\hline
\end{tabular}

\begin{tabular}{lllllll}
\hline 4 & & & & & & \\
5 & Chinese food & 4.2642 & 0.3057 & 1.4245 & 1.0757 & 0.5274 \\
6 & Chinese fast food & 9.5131 & 0.2833 & 3.0463 & 2.5664 & 1.4086 \\
7 & Western fast food & 4.7364 & 0.2384 & 1.5133 & 1.4980 & 1.1438 \\
8 & The cake & 2.6827 & 0.6915 & 1.6784 & 1.5815 & 1.1949 \\
9 & Bread & 7.1138 & 0.6180 & 1.5013 & 1.3629 & 0.9088 \\
10 & Snacks & 6.8578 & 0.2472 & 1.8651 & 1.5181 & 0.7643 \\
11 & Milk tea & 6.9390 & 0.2433 & 1.8162 & 1.5570 & 1.1878 \\
12 & Dessert/drinks & 3.6872 & 0.3528 & 1.7837 & 1.8278 & 1.4504 \\
& & & & & & \\
\hline
\end{tabular}

Table 3.4 Summary of RMSE for Different Types of Shops

\begin{tabular}{lllllll}
\hline Number & Categorical variables & Max & Min & Mean & Median & $1^{\text {st }} \mathrm{Qu}$ \\
\hline 1 & The convenience store & 16.5640 & 0.4280 & 3.6790 & 3.3110 & 2.6310 \\
2 & The supermarket & 6.4196 & 0.4943 & 2.4922 & 2.4745 & 1.9957 \\
3 & Hot pot & 2.0058 & 0.5361 & 0.8036 & 0.6520 & 0.6005 \\
4 & Chinese food & 3.5521 & 0.3950 & 1.2847 & 1.0362 & 0.5912 \\
5 & Chinese fast food & 7.9831 & 0.3177 & 2.5786 & 2.0386 & 1.3636 \\
6 & Western fast food & 3.8453 & 0.3285 & 1.3989 & 1.3760 & 1.0734 \\
7 & The cake & 2.7006 & 0.6544 & 1.5107 & 1.4314 & 1.1747 \\
8 & Bread & 5.4436 & 0.3960 & 1.3452 & 1.2470 & 0.8805 \\
9 & Snacks & 6.5486 & 0.3497 & 1.6365 & 1.3419 & 0.7432 \\
10 & Milk tea & 5.5757 & 0.4045 & 1.6288 & 1.4581 & 1.1433 \\
11 & Dessert/drinks & 3.1568 & 0.4692 & 1.5848 & 1.6525 & 1.3258 \\
12 & Fresh fruit & 4.8013 & 0.6834 & 2.1747 & 2.0637 & 1.7829 \\
\hline
\end{tabular}

The above two tables of data according to different categories are drawn into a box chart, as shown in Figure 3.2:

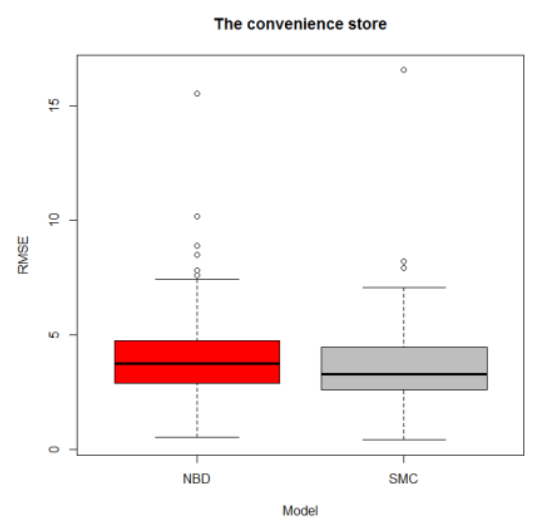

Fig. 3.2(a)

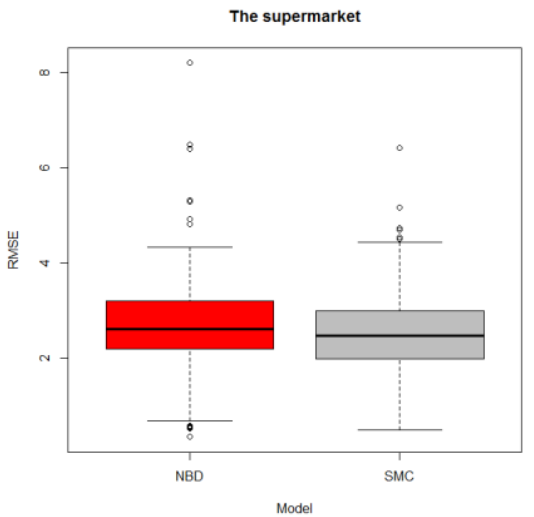

Fig. 3.2(b) 


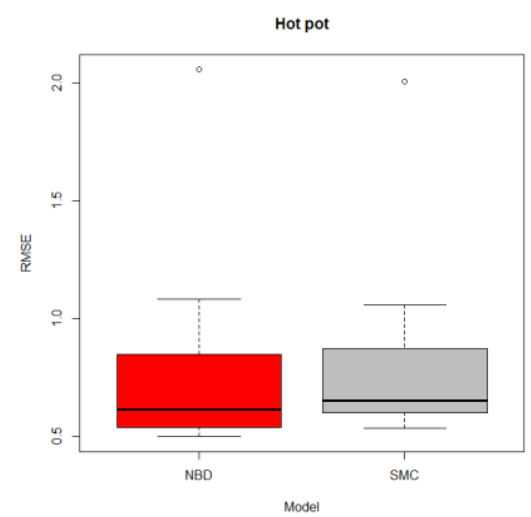

Fig. 3.2(c)

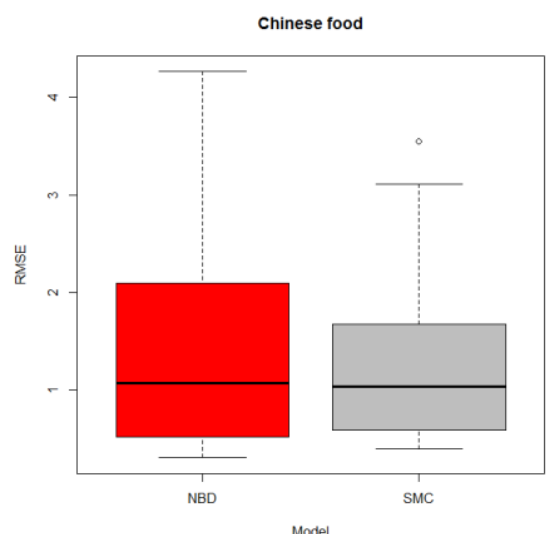

Fig. 3.2(d)

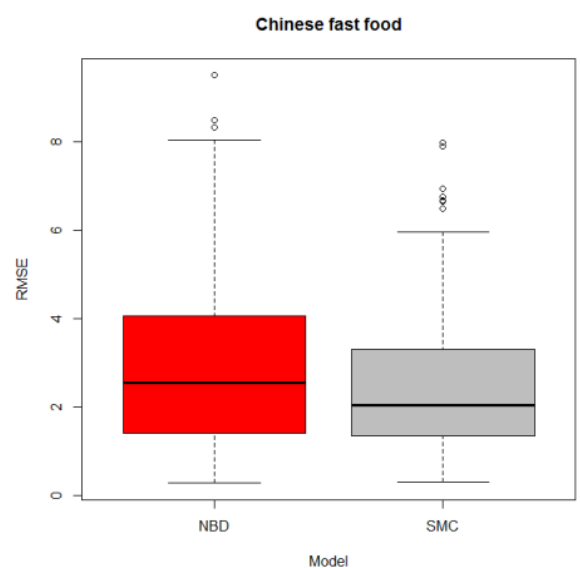

Fig. 3.2(e)

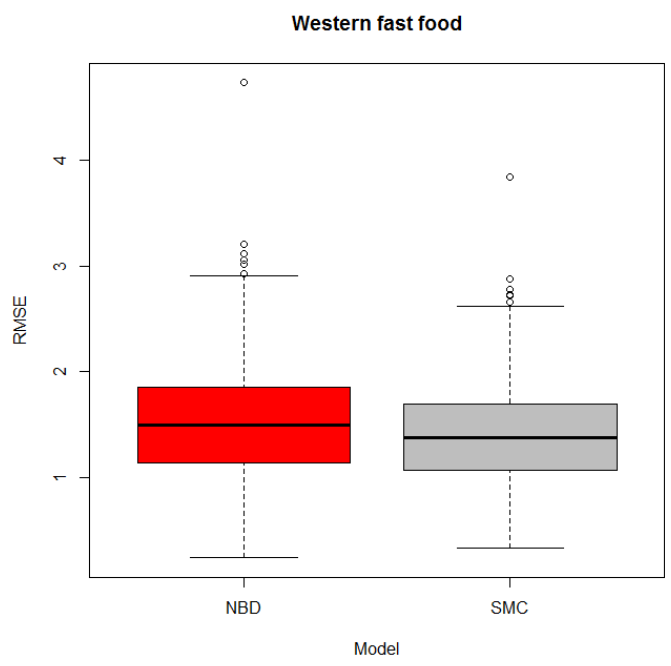

Fig. 3.2(f)

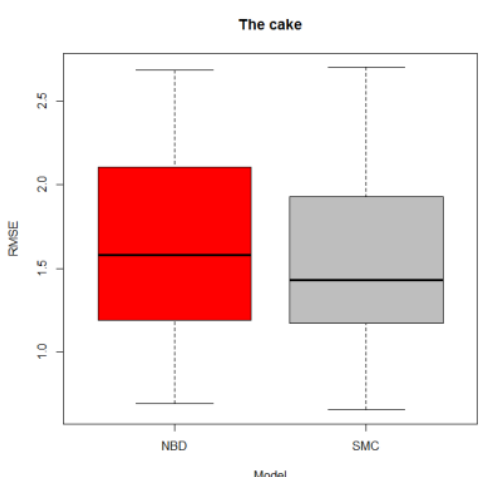

Fig. $3.2(\mathrm{~g})$

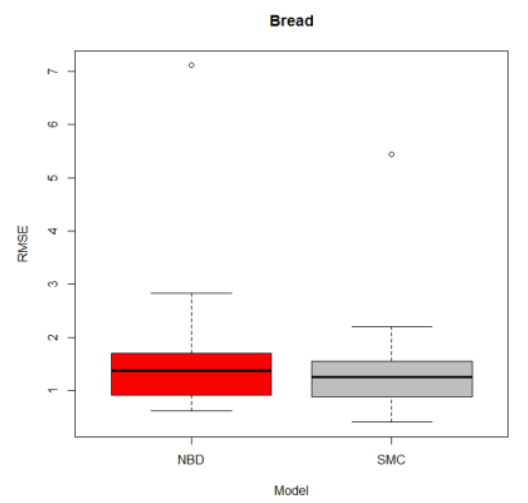

Fig. 3.2(h)

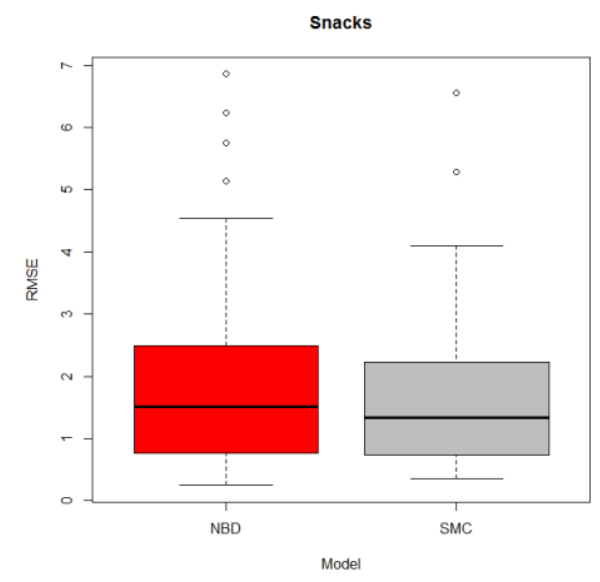

Fig. 3.2(i)

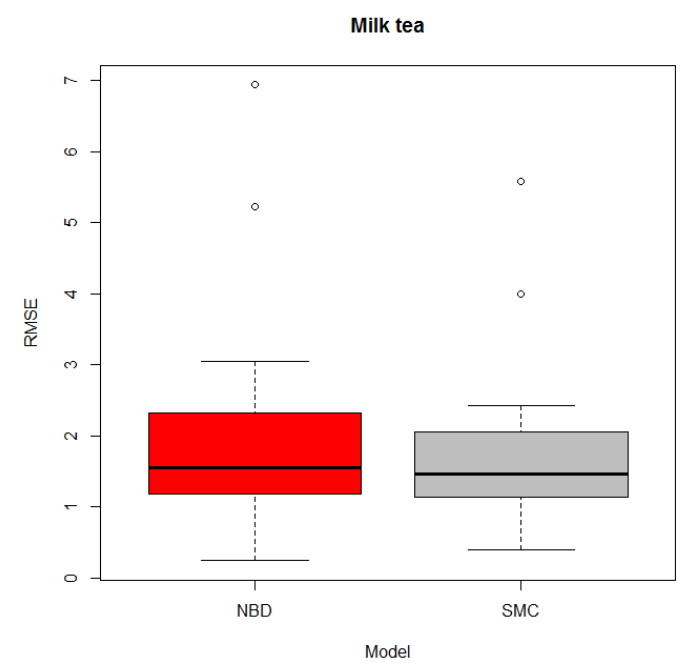

Fig. 3.2(j) 


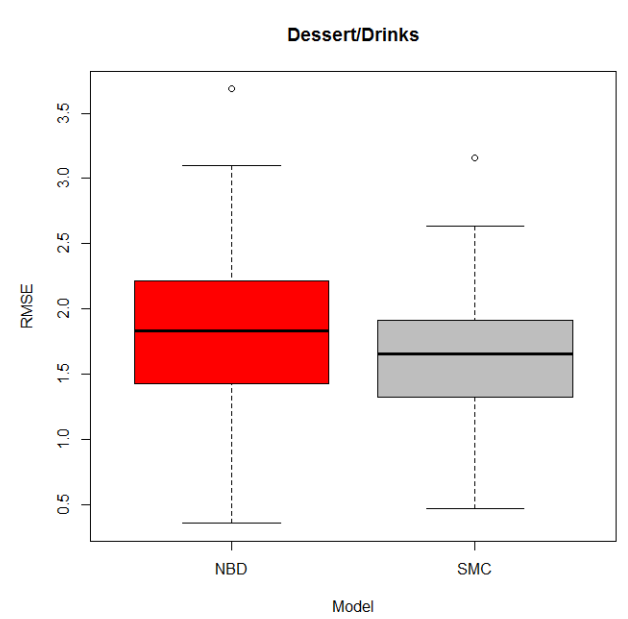

Fig. 3.2(k)

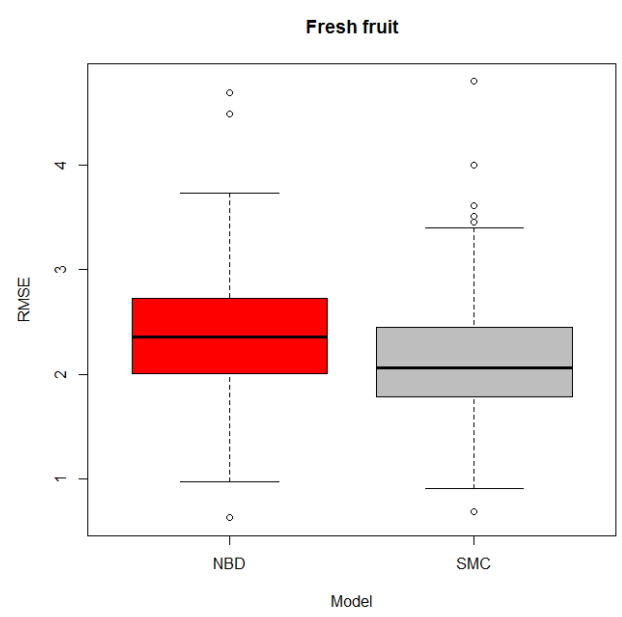

Fig. 3.2(l)

Fig.3.2 Predicted Results (RMSE) of SMC Model and NBD Model

The results shows that, in addition to the hot pot category, predicted results of the SMC model in each category of business is better than the
NBD model, while the NBD model is more excellent in the forecast of the hot pot category. The SMC results are the best in these categories, such as Western fast food, Chinese food, bread, cake, milk tea, dessert/drink and snack. In the supermarket, fresh fruit, Chinese fast food these three categories to predict the effect slightly, for the convenience store category prediction effect is the worst.

\section{Conclusions}

The results shows that, in addition to the hot pot category, predicted results of the SMC model in each category of business is better than the NBD model, while the NBD model is more excellent in the forecast of the hot pot category. Although the empirical analysis of this study has been supported by specific business data, there are still some limitations. In the empirical data section, you can collect more different categories of business data, improve the empirical study.

\section{References}

[1] Alex, R.: Why online to offline commerce is a trillion dollar opportunity. TechCrunch, Vol.11, No.10, 2011.

[2] Phang C W, Tan C H, Sutanto J, et al. Leveraging O2O Commerce for Product Promotion: An Empirical Investigation in Mainland China[J]. IEEE Transactions on Engineering Management, 2014, 61(4):623-632.

[3] Jia-Yin, Q. I., et al: Positive Research of SMC Models in IT Distribution Market Industry. Systems Engineering-theory \& Practice 24.3(2004):6978.

[4] Schmittlein, David C., D. G. Morrison, and R. Colombo: Counting your customers: who are they and what will they do next?. INFORMS, 1987.

[5] Batislam E P, Denizel M, Filiztekin A: Empirical validation and comparison of models for customer base analysis [J]. International Journal of Research in Marketing, 2007, 24(3):201-209.

[6] Fader P S, Hardie B G S. RFM and CLV: Using Iso-Value Curves for Customer Base Analysis [J]. Journal of Marketing Research, 2005, 42(4):415-430

[7] Shao-Hui M A: Empirical Study on Pareto/NBD Model and Its Applications [J].Management Sciences in China, 2006.

[8] Ma, Shao Hui, and J. L. Liu: The MCMC Approach for Solving the Pareto/NBD Model and Possible Extensions. International Conference on Natural Computation IEEE Computer Society, 2007:505-512. 